\title{
Increased Ruminoreticular Temperature and Body Activity after Foot-and-Mouth Vaccination in Pregnant Hanwoo (Bos taurus coreanae) Cows
}

\author{
Daehyun Kim ${ }^{1}{ }^{1}$, Jaejung Ha ${ }^{1}$, Joonho Moon ${ }^{2}$, Doyoon Kim ${ }^{3}$, Wonhee Lee ${ }^{4}$, Chanwoo Lee ${ }^{4}$, Danil Kim ${ }^{5, *}$ \\ and Junkoo Yi ${ }^{1, * \mathbb{D}}$
}

check for updates

Citation: Kim, D.; Ha, J.; Moon, J.; Kim, D.; Lee, W.; Lee, C.; Kim, D.; Yi, J. Increased Ruminoreticular Temperature and Body Activity after Foot-and-Mouth Vaccination in Pregnant Hanwoo (Bos taurus coreanae) Cows. Vaccines 2021, 9, 1227. https://doi.org/10.3390/ vaccines 9111227

Academic Editors: François Meurens and Elizabeth Rieder

Received: 30 August 2021

Accepted: 19 October 2021

Published: 22 October 2021

Publisher's Note: MDPI stays neutral with regard to jurisdictional claims in published maps and institutional affiliations.

Copyright: (c) 2021 by the authors. Licensee MDPI, Basel, Switzerland. This article is an open access article distributed under the terms and conditions of the Creative Commons Attribution (CC BY) license (https:/ / creativecommons.org/licenses/by/ $4.0 /)$.
1 Livestock Research Institute, Gyeongsangbuk-Do, 186 Daeryongsan-ro, Anjeong-myeon, Yeongju 36052, Korea; chunja2411@korea.kr (D.K.); hjjggo@korea.kr (J.H.)

2 Lartbio Co., Ltd., 12th Floor, 234 Teheran-ro, Gangnam-gu, Seoul 06221, Korea; kuma618@gmail.com

3 Department of Animal Science and Biotechnology, Kyungpook National University, Sangju 41566, Korea; kdy51311@naver.com

4 Department of Biotechnology, College of Agriculture \& Life Science, Hankyong National University, Ansung 17579, Korea; wonhee0625@naver.com (W.L.); rhdaud2299@naver.com (C.L.)

5 Institute of Green-Bio Science and Technology, Seoul National University, Seoul 25354, Korea

* Correspondence: danilkim73@snu.ac.kr (D.K.); 79lee38@korea.kr (J.Y.); Tel.: +82-33-339-6102 (D.K.); +82-54-630-4542 (J.Y.)

\begin{abstract}
How does vaccination against foot-and-mouth disease (FMD) affect pregnant cows? Vaccination is the most effective method of preventing the spread of FMD, but it is linked to sporadic side effects, such as abortion and premature birth, which result in economic loss. In this study, ruminoreticular temperature and body activity were measured before and after FMD vaccination using a ruminoreticular biocapsule sensor in Hanwoo cows at different stages of pregnancy. Compared to the unvaccinated groups, the ruminoreticular temperature increased $12 \mathrm{~h}$ after vaccination in the vaccinated groups. This increase in temperature is significantly correlated to vaccination. Compared to the nonpregnant and early pregnancy groups, the ruminoreticular temperature of the late pregnancy group increased sharply by more than $40^{\circ} \mathrm{C}$. Moreover, in nonpregnant and early pregnancy groups, a rapid increase in body activity was observed after FMD vaccinations. Of the 73 pregnant vaccinated cows in the study, a total of five cases had side effects (four abortions and one premature birth). Therefore, changes in the ruminoreticular temperature and activity in pregnant cows can be used as raw data to further clarify the association of FMD vaccination with the loss of a fetus and possibly predict abortion, miscarriage, and premature birth following FMD vaccination.
\end{abstract}

Keywords: ruminal biocapsule sensor; FMD vaccination; ruminoreticular temperature; body activity; abortion; premature birth; Korean cattle

\section{Introduction}

Foot-and-mouth disease (FMD) is an infectious disease that causes serious economic losses in the cattle industry and occurs in many countries in North America, Western Europe, South America, and Asia [1]. As vaccination is the most effective way to prevent FMD, many countries have made it obligatory [2,3]. Various types of FMD vaccines, including adeno- and viral vector-based vaccines, virus-like particles, peptide and DNA vaccines, plant-based vaccines, and inactivated vaccines, have been developed. The inactivated FMD vaccine is the most commonly used [4-8].

Unfortunately, there are reports of unfavorable side effects following FMD vaccination in cattle, e.g., early embryo loss, low sperm fertility, decreased milk production, increased acute-phase reaction and anovulation, and increased ruminal temperature in nonpregnant cows [8-11]. In addition, it has been reported that the level of inflammatory cytokines and gene expression can increase due to the acute-phase immune response and that the innate 
immune response can be induced by the oil-based adjuvant in the FMD vaccine $[3,8,12,13]$. FMD vaccination 30 days after artificial insemination has been reported to increase rectal temperature, early embryo loss, and haptoglobin levels in the blood of cattle. Increases in temperature and haptoglobin levels are highly correlated with an acute-phase immune response $[8,10]$.

The most common clinical symptoms of the FMD virus in Korean cattle are increased body temperature, decreased appetite, blisters (in the mouth, tongue, hooves, and nipples), and miscarriage [14]. In previous studies, we confirmed the increased ruminoreticular temperature and acute immune response after FMD vaccination in nonpregnant cows [11]. However, there are no reports on changes in ruminoreticular temperature and body activity following FMD vaccination or on unfavorable side effects associated with pregnancy, such as abortion or premature birth. Therefore, this study aims to examine the differences in ruminoreticular temperature and body activity relative to pregnancy stage after FMD vaccination in Hanwoo cows.

\section{Materials and Methods}

\subsection{Animals and Management}

This study examined 203 cows (63 cows pregnant for over 210 days bred in a space of $10 \mathrm{~m}^{2} / \mathrm{cow}, 72$ cows pregnant for over 80 days, and 68 nonpregnant cows both bred in a space of $20 \mathrm{~m}^{2} / \mathrm{cow}$ ) equipped with a ruminoreticular biocapsule sensor and reared in the same farm (Gyeongsangbuk-Do Livestock Research Institute). Detailed information on the age of the cows, days of pregnancy, and age at vaccination in the experimental groups is shown in Table 1. Cows were fed according to the Korean Cattle Feeding Management Regulations and kept in a breeding space conforming to legal requirements $\left(>10 \mathrm{~m}^{2} / \mathrm{cow}\right)$, with a stanchion installed. All experiments were conducted with the approval of the Animal Ethics Committee of the Gyeongsangbuk-do Livestock Research Institute (Approval number: \#106).

Table 1. Information for experimental groups $(n=203)$. NP, nonpregnant; <P80, pregnant for less than 80 days; $>$ P120, pregnant for over 120 days.

\begin{tabular}{|c|c|c|c|c|c|}
\hline \multicolumn{2}{|c|}{ Group } & $\mathbf{n}$ & Months of Age & Days of Pregnancy & Breeding Space \\
\hline \multirow{3}{*}{ Control } & $\mathrm{NP}$ & 29 & $44.3 \pm 2.9$ & 0 & \multirow{2}{*}{$300 \mathrm{~m}^{2} / 15$ cows } \\
\hline & $<\mathrm{P} 80$ & 28 & $42.7 \pm 2.0$ & $57.5 \pm 3.0$ & \\
\hline & $>\mathrm{P} 210$ & 34 & $50.4 \pm 2.7$ & $258.6 \pm 2.7$ & $20 \mathrm{~m}^{2} / 2$ cows \\
\hline \multirow{3}{*}{$\begin{array}{c}\text { FMD } \\
\text { Vaccinated }\end{array}$} & $\mathrm{NP}$ & 39 & $34.3 \pm 2.4$ & 0 & \multirow{2}{*}{$300 \mathrm{~m}^{2} / 15$ cows } \\
\hline & $<\mathrm{P} 80$ & 44 & $38.5 \pm 1.6$ & $49.9 \pm 2.3$ & \\
\hline & $>\mathrm{P} 210$ & 29 & $42.5 \pm 3.4$ & $256.9 \pm 3.2$ & $20 \mathrm{~m}^{2} / 2$ cows \\
\hline \multicolumn{2}{|c|}{ Total } & 203 & $42.1 \pm 3.8$ & - & - \\
\hline
\end{tabular}

\subsection{Real-Time Measurement of Ruminoreticular Temperature and Body Activity}

The ruminoreticular temperature and body activity were measured with the biocapsule sensor for 30 days after vaccination. Information on the biocapsule sensor (LiveCare; uLikeKorea, Seoul, Korea) used to measure ruminoreticular temperature and measurement of body activity can be found in the work of Kim and Choi et al. [15-17]. Body activity (V) is expressed as the root value of the sum of $X^{2}+Y^{2}+Z^{2}$ measured with an indwelling 3-axis accelerometer (X, Y, and Z). Detailed information on this technique has been reported [17].

\subsection{FMD Vaccination}

The FMD vaccine (Daesung microbiological labs co., FMD vaccine, O manisa, O3039, A22 Iraq, Seoul, Korea) was administered intramuscularly with Anti-VS-2 Inj. (Samyang 
Anipharm Co., Pocheon, Korea) for vaccine stress relief. The same dose of FMD vaccine from the same batch was injected intramuscularly into the necks of the cattle.

\subsection{Pregnancy Test}

The pregnancy state of the cattle was evaluated through rectal ultrasonography (HONDA HS-101V, HONDA Co., Ltd., Tokyo, Japan) 10 days before the initiation of the experiment. An additional pregnancy test was performed to determine whether miscarriage had occurred 10 days after FMD vaccination.

\subsection{Statistical Analysis}

The PRISM program (version: 8.1.0) was used for statistical analysis. Average ruminoreticular temperature and body activity before and after FMD vaccination were compared for each of the 3 groups through two-way ANOVA (Tukey's multiple comparison test) for each $6 \mathrm{~h}$ period. The significance level was set at ${ }^{*} p<0.05,{ }^{* *} p<0.01$, and ${ }^{* * *} p<0.001$.

\section{Results}

\subsection{Change of Ruminoreticular Temperature and Body Activity following FMD Vaccination}

For nonpregnant cows (NP), the vaccinated group is hereinafter referred to as "FMD_NP", and the unvaccinated group as "Control_NP" (Figures 1A and 2A and Table 1). For cows pregnant for less than 80 days, the vaccinated group is hereinafter referred to as "FMD < P80" and the unvaccinated group as "Control < P80" (Figures 1B and 2B and Table 1). For cows pregnant for more than 210 days, the vaccinated group is hereinafter referred to as "FMD > P210", and the unvaccinated group as "Control > P210" (Figures $1 \mathrm{C}$ and $2 \mathrm{C}$ and Table 1 ).

The ruminoreticular temperature of all the test groups gradually increased starting at $12 \mathrm{~h}$ after the vaccination (Figure $1, p<0.005$ ). The ruminoreticular temperature of the FMD_NP group $12 \mathrm{~h}$ after vaccination $\left(39.1 \pm 0.09^{\circ} \mathrm{C}\right)$ was higher than that the unvaccinated Control_NP group $\left(38.6 \pm 0.00{ }^{\circ} \mathrm{C}\right)$ remained at (Figure 1A). The ruminoreticular temperature of the FMD $<$ P80 group $12 \mathrm{~h}$ after vaccination $\left(39.3 \pm 0.09^{\circ} \mathrm{C}\right)$ was higher than that of the Control $<$ P80 group $\left(38.5 \pm 0.05^{\circ} \mathrm{C}\right)$ (Figure 1B). The ruminoreticular temperature in the FMD $>$ P210 group $12 \mathrm{~h}$ after vaccination $\left(39.9 \pm 0.18^{\circ} \mathrm{C}\right)$ was significantly higher than the Control $>$ P210 group $\left(39.0 \pm 0.06^{\circ} \mathrm{C}\right)$ (Figure 1C).

At the time of FMD vaccination, a rapid increase in body activity was observed in the FMD_NP $(1846.7 \pm 133.7 \mathrm{~V})$ and FMD $<$ P80 groups $(2156.1 \pm 117.7 \mathrm{~V})$ but did not change in the FMD > P210 group (1251.5 $\pm 41.3 \mathrm{~V})$ (Figure 2). The body activity of the FMD_NP group increased $(1846.7 \pm 133.7 \mathrm{~V})$ but did not change in the Control_NP group $(1251.1 \pm 13.2 \mathrm{~V})$ (Figure 2A). At the time of FMD vaccination, the body activity of the FMD $<$ P80 group was higher $(2156.1 \pm 117.7 \mathrm{~V})$ than that of the Control $<$ P80 group $(1232.6 \pm 6.2 \mathrm{~V})$ (Figure 2B). There was no difference when comparing the body activity at the time of FMD vaccination in the FMD > P210 group (1251.5 $\pm 41.3 \mathrm{~V})$ and the Control > P210 group (1229.4 $\pm 6.8 \mathrm{~V})$ (Figure 2C).

\subsection{Cases of Abortion and Premature Birth following FMD Vaccination}

In this study, after FMD vaccination, a total of $5(6.8 \%)$ out of 73 pregnant cows experienced abortions and premature births, with four abortions and one premature birth identified by clinical criteria. There were no abortions or premature deliveries in unvaccinated cows. The death of the aborted or premature calves was confirmed visually and measurements were taken to determine the fetal length and weight. 

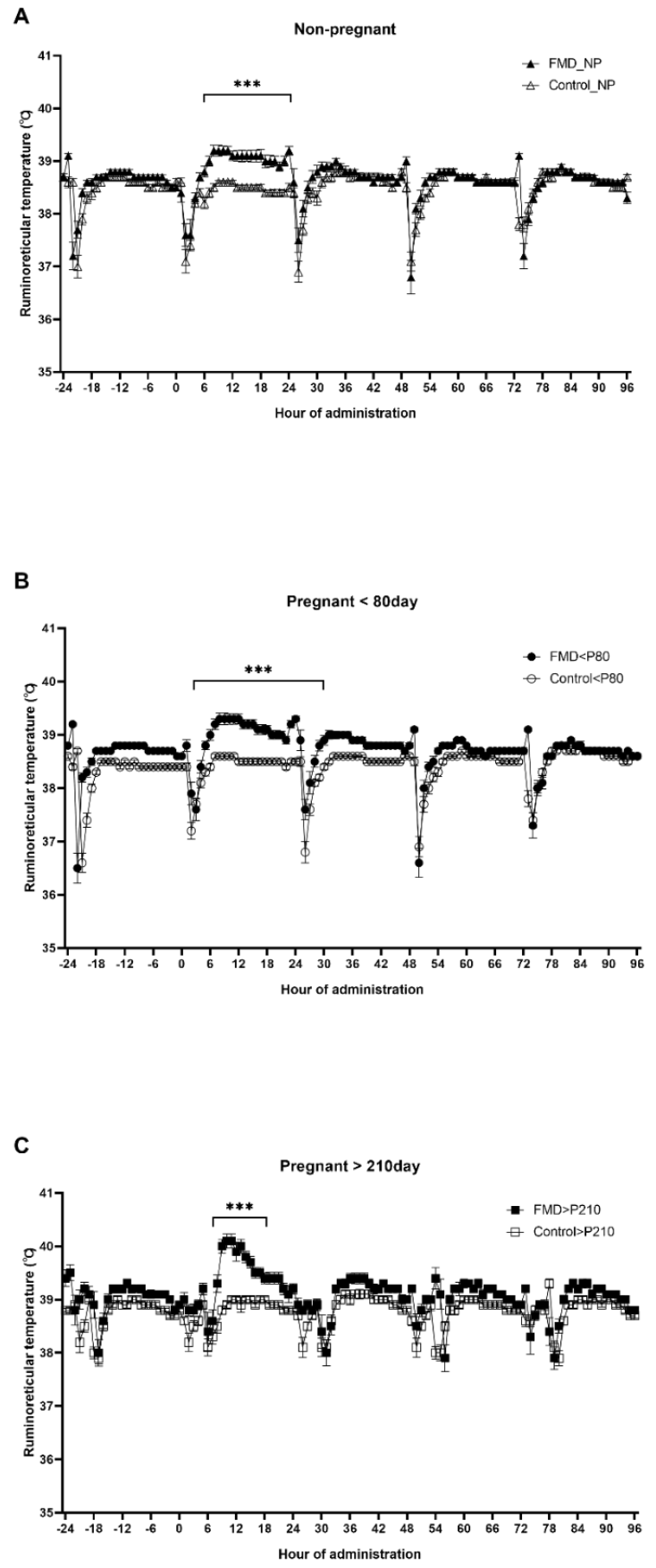

Figure 1. Change in ruminoreticular temperature depending on pregnancy and FMD vaccination $(n=203)$. (A) Ruminoreticular temperature of control and FMD-vaccinated nonpregnant cows. The black line connected by " $\triangle$ " represents the mean temperature of the Control_NP group (not vaccinated). The black line connected by " $\mathbf{\Delta}$ " represents the mean temperature of the FMD_NP group (vaccinated). (B) Ruminoreticular temperature of control and FMD-vaccinated cows pregnant for less than 80 days. The black line connected by " $\bigcirc$ " represents the mean temperature of the Control $<$ P80 group (not vaccinated). The black line connected by "•" represents the mean temperature of the FMD < P80 group (vaccinated). (C) Ruminoreticular temperature of control and FMD-vaccinated cows pregnant for more than 210 days. The black line connected by " $\square$ " represents the mean temperature of the Control > P210 group (not vaccinated). The black line connected by " $\mathbf{\square}$ " represents the mean temperature of the FMD > P210 group (vaccinated). Day 0 is the time of the FMD vaccination and the error bar is the standard error of the mean. ${ }^{* * *}$ means significance level $p<0.001$. 
A

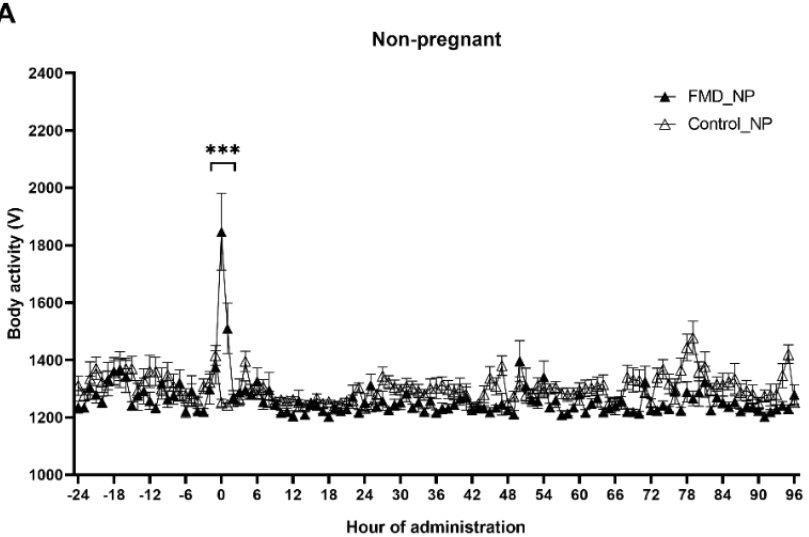

B
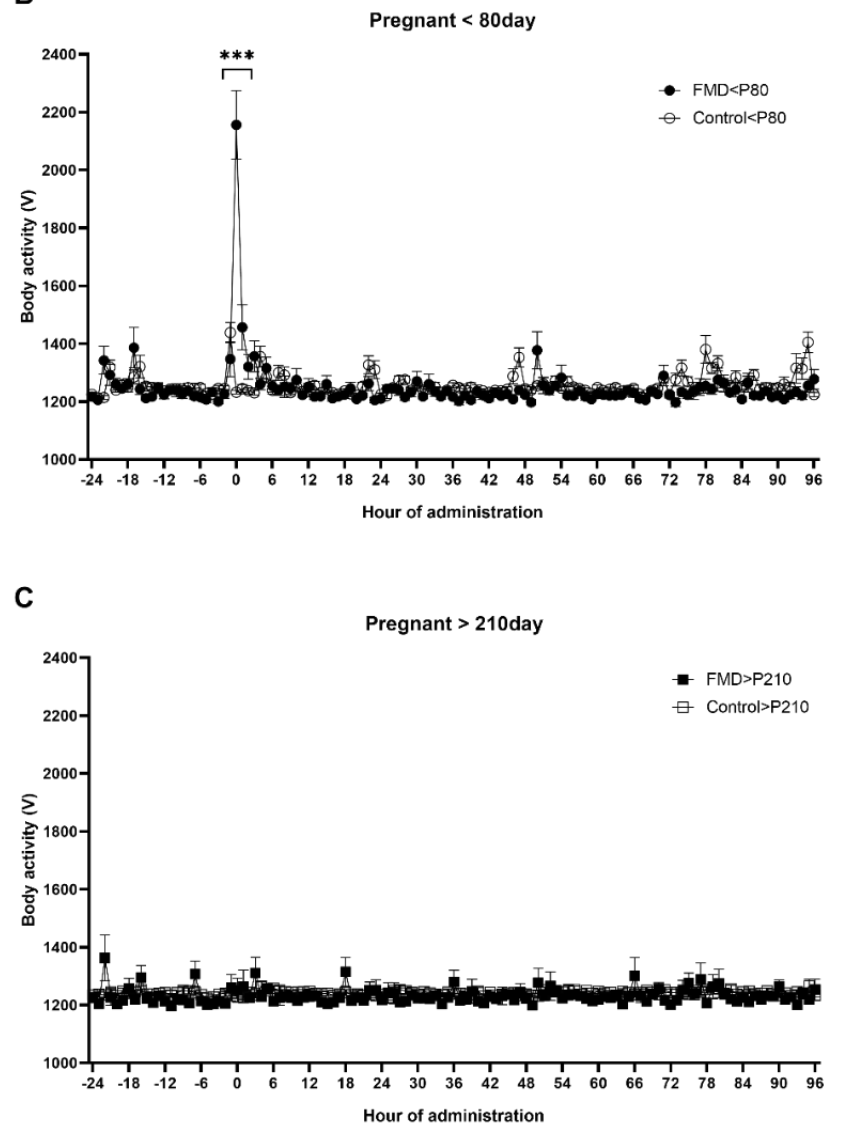

Figure 2. Change in body activity depending on pregnancy and FMD vaccination $(n=203)$. (A) Body activity of control and FMD-vaccinated nonpregnant cows. The black line connected by " $\triangle$ " represents the mean movement of the Control_NP group (not vaccinated). The black line connected by " $\boldsymbol{\Delta}$ " represents the mean movement of the FMD_NP group (vaccinated). (B) Body activity of control and FMD-vaccinated groups of cows pregnant for less than 80 days. The black line connected by " $\bigcirc$ " represents the mean movement of the Control < P80 group (not vaccinated). The black line connected by "•" represents the mean movement of the FMD $<$ P80 group (vaccinated). (C) Body activity of control and FMD vaccination group in cows pregnant for over 120 days. The black line connected by " $\square$ " represents the mean movement of the Control > P210 group (not vaccinated). The black line connected by " $\mathbf{\square}$ " represents the mean movement of the FMD > P210 group (vaccinated). Day 0 is the time of the FMD vaccination and error bar is the standard error of the mean. ${ }^{* * *}$ means significance level $p<0.001$. 
In premature birth \#13-81, the cow was vaccinated on the 274th day of pregnancy. It showed a rapid increase in ruminoreticular temperature $12 \mathrm{~h}$ after vaccination. The birth weight of the calf was $22 \mathrm{~kg}$ (Figure S1).

In case \#433, the cow was vaccinated on the 267th day of pregnancy. It showed a low ruminoreticular temperature immediately after vaccination and delivered $26 \mathrm{~h}$ after vaccination. However, the calf was born 18 days early and died immediately after delivery. Its birth weight was $20 \mathrm{~kg}$ (Figure S2).

In case \#17-25, the cow was vaccinated on the 210th day of pregnancy. It showed a high ruminoreticular temperature of $40^{\circ} \mathrm{C} 18 \mathrm{~h}$ after vaccination, and the fetus was aborted 4 days after vaccination. The aborted fetus was $65 \mathrm{~cm}$ long and weighed $13 \mathrm{~kg}$ (Figure S3).

In case \#425, the cow was vaccinated on the 68th day of pregnancy. It experienced an abortion 4 days after vaccination, and the aborted fetus died. The occurrence of miscarriage was immediately reconfirmed through a rectal examination using ultrasound equipment, but the aborted fetus could not be visually confirmed (Figure S4).

In case \#398, the cow was vaccinated on the 47 th day of pregnancy. It showed a high ruminoreticular temperature of $40^{\circ} \mathrm{C}$ at $12 \mathrm{~h}$ after vaccination and experienced an abortion 5 days after vaccination (Figure S5). Although the cow was examined through ultrasound equipment, the fetus could not be visually confirmed, as in case \#425.

\section{Discussion}

The association of ruminoreticular temperature and body activity with FMD vaccination was analyzed in Korean cattle. After vaccination, the ruminoreticular temperature rose between 12 to $30 \mathrm{~h}$, and body activity transiently increased at the time of vaccination. The correlation between a rise in ruminoreticular temperature and vaccination was statistically significant. A total of 203 cows ( 63 cows pregnant for over 210 days, 72 cows pregnant for over 80 days, and 68 nonpregnant cows) were tested for adverse effects following FMD vaccination, so the ruminoreticular temperature and body activity of pregnant cows could be examined in detail. In unvaccinated controls, the body temperature could conceivably rise temporarily due to a placebo effect. However, a previous study, in which $0.9 \%$ normal saline was injected instead of the FMD vaccine, obtained similar results, supporting the lack of a placebo effect [11]. Therefore, the results of this study are likely not due to a placebo effect.

A total of five cows experienced abortions and premature births following FMD vaccination. There were no changes in the external environment (movement of space, cleanliness, construction, etc.) before and after the test period. Therefore, these events are most likely due to the vaccination.

Studies have reported that cow parity, breeding season, insemination protocol, and calving interval affect the incidence of pregnancy loss [18]. In addition, it has been reported that when artificial insemination is performed 30 days after FMD vaccination early embryo loss were more frequent. On the meantime authors reported increases in rectal temperature and in acute immune response protein (haptoglobin) in the blood [8]. Therefore, we hypothesize that the cause of miscarriage and premature birth is an acute immune response to FMD vaccination, but the exact reason is still unclear. Additionally, methods for validating abortions and preterm births due to FMD vaccination are not yet established. It is generally accepted that the main causes of miscarriage in cattle are heat stress, season, milk production, high environmental temperature, vaccination, and bacterial infection [18-20]. The general incidence of such miscarriages has been reported to be from 2 to $5 \%$ and to occur most frequently at 30-60 days of gestation [21-23]. The average prevalence of miscarriage in this study was $6.8 \%$ among 73 pregnant cows at the time of vaccination. It was not possible to compare this statistically to previously reported prevalence estimates due to the small number of cases and lack of an appropriate comparison group.

The cases of abortion on the 47th and 68th days of gestation could be considered as embryo losses. However, we classified them as abortions in this study because there were no other environmental changes other than the FMD vaccination. In the case of abortion 
or premature birth after FMD vaccination, numerous tests for bacteria and viruses are required to scientifically demonstrate the cause and mechanism. Once the role of bacteria and viruses is disconfirmed using the reported methods, the effect of FMD vaccination on abortion can be estimated, but the exact result cannot be known. A method that can completely verify abortion, premature birth, and early embryo loss due to FMD vaccination has not yet been developed.

In addition, as shown in Figure 1, the temporary decrease in ruminoreticular temperature occurred at similar times every day. The main cause of this phenomenon is the intake of drinking water accompanied by feed intake, and because the biosensor is in the rumen and reticulum, a temporary drop in temperature can be seen. Similar results due to water consumption have been reported elsewhere [24,25].

In the case of pregnancies longer than 210 days, it is possible to confirm that the temporal ruminoreticular temperature pattern is different because those cows were fed after $6 \mathrm{~h}$ (fed at 4:00 PM), unlike cows that were pregnant for less than 80 days and nonpregnant cows (fed at $10 \mathrm{AM}$ ), which is carried out to induce birthing at sunrise (Figure 1C).

Additional findings in this study were that after FMD vaccination, relative to the Control > P210 group, the ruminoreticular temperature increased the most in the FMD > P210 group, but there was no difference in body activity. We postulate that the reason for this lack of difference in body activity among cows that are pregnant for more than 210 days is because nonpregnant cows and cows pregnant for less than 80 days are bred in a larger space of $300 \mathrm{~m}^{2} / 15$ cows $\left(20 \mathrm{~m}^{2} / \mathrm{cow}\right)$, whereas cows with over 210 days of pregnancy are bred in a space of only $20 \mathrm{~m}^{2} / 2$ cows $\left(10 \mathrm{~m}^{2} / \mathrm{cow}\right)$ to avoid damage to the calves. Therefore, the likely lack of difference in activity in cows at over 210 days of pregnancy is due to their narrow breeding space.

\section{Conclusions}

In summary, data on changes in ruminoreticular temperature and body activity can be used as raw data for the further correlation of abortion and premature birth to FMD vaccination. Rises in ruminoreticular temperature are particularly useful due to their strong correlation with vaccination. This will allow for the prediction of abortion and premature birth after vaccination and help in drug development to prevent adverse effects. These findings could ultimately lead to the development of an artificial intelligence system that can manage these predictions.

Supplementary Materials: The following are available online at https:/ / www.mdpi.com/article/ 10.3390 /vaccines9111227/s1, Figure S1: Ruminoreticular temperature and activity in the case of premature birth (\#13-81, 274th day of pregnancy), Figure S2: Ruminoreticular temperature and activity in a case of abortion (\#433, 267th day of pregnancy), Figure S3: Ruminoreticular temperature and activity in a case of abortion (\#17-25, 210th day of pregnancy), Figure S4: Ruminoreticular temperature and activity in a case of abortion (\#425,68th day of pregnancy), Figure S5: Ruminoreticular temperature and activity in a case of abortion (\#398, 47th day of pregnancy).

Author Contributions: Conceptualization: D.K. (Daehyun Kim), J.H., and J.Y.; methodology: D.K. (Daehyun Kim), J.H., D.K. (Doyoon Kim), W.L., and C.L.; investigation: J.H., D.K. (Doyoon Kim), W.L., and C.L.; visualization: D.K. (Daehyun Kim) and J.M.; supervision: D.K. (Danil Kim) and J.Y.; writing—original draft: D.K. (Daehyun Kim); writing—review and editing: D.K. (Daehyun Kim), D.K. (Danil Kim), and J.Y. All authors have read and agreed to the published version of the manuscript.

Funding: Financial support for this study was granted by the Korea Institute of Planning and Evaluation for Technology in Food, Agriculture, Forestry (IPET) through a Food, Agriculture, Technology convergence creative talent training project funded by the Ministry of Agriculture, Food, and Rural Affairs (MAFRA) (120011021) and a National Research Foundation of Korea (NRF) grant funded by the Korea government (MSIT; No. NRF-2020R1F1A1052024). 
Institutional Review Board Statement: The study was conducted according to the guidelines of the Declaration of Helsinki, and approved by Institutional Animal Care and Use Committee (IACUC) of the Gyeongsangbuk-do Livestock Research Institute, Yeongju, Korea (protocol code GAEC/127/19 approved at 7 December 2019).

Informed Consent Statement: Informed consent was obtained from all subjects involved in the study.

Data Availability Statement: Not applicable.

Acknowledgments: This research was supported by Gyeongsangbuk-Do Livestock Research Institute. The research project title was "Improvement of managing technology using real-time biometric information in Korean cattle".

Conflicts of Interest: The authors declare no conflict of interest. The funders had no role in the design of the study; in the collection, analyses, or interpretation of data; in the writing of the manuscript, or in the decision to publish the results.

\section{References}

1. Grubman, M.J.; Baxt, B. Foot-and-mouth disease. Clin. Microbiol. Rev. 2004, 17, 465-493. [CrossRef]

2. Kahn, S.; Geale, D.W.; Kitching, P.R.; Bouffard, A.; Allard, D.G.; Duncan, J.R. Vaccination against foot-and-mouth disease: The implications for Canada. Can Vet. J. 2002, 43, 349-354.

3. Rodriguez, L.L.; Grubman, M.J. Foot and mouth disease virus vaccines. Vaccine 2009, 27 (Suppl. 4), D90-D94. [CrossRef]

4. Zhang, L.; Zhang, J.; Chen, H.-T.; Zhou, J.-H.; Ma, L.-N.; Ding, Y.-Z.; Liu, Y.-S. Research in advance for FMD novel vaccines. Virol. J. 2011, 8, 268. [CrossRef] [PubMed]

5. Singh, R.K.; Sharma, G.K.; Mahajan, S.; Dhama, K.; Basagoudanavar, S.H.; Hosamani, M.; Sreenivasa, B.P.; Chaicumpa, W.; Gupta, V.K.; Sanyal, A. Foot-and-mouth disease virus: Immunobiology, advances in vaccines and vaccination strategies addressing vaccine failures-an indian perspective. Vaccines 2019, 7, 90. [CrossRef] [PubMed]

6. Kamel, M.; El-Sayed, A.; Castaneda Vazquez, H. Foot-and-mouth disease vaccines: Recent updates and future perspectives. Arch. Virol. 2019, 164, 1501-1513. [CrossRef]

7. Shahriari, A.; Habibi-Pirkoohi, M. Developing vaccines against foot-and-mouth disease: A biotechnological approach. Arch. Razi. Inst. 2018, 73, 1-10. [CrossRef] [PubMed]

8. $\quad$ Ferreira, L.C.; Cooke, R.F.; Marques, R.S.; Fernandes, H.J.; Fernandes, C.E.; Stelato, R.; Franco, G.L.; Lemos, R.A.A. Effects of vaccination against foot-and-mouth disease virus on reproductive performance of beef cows. J. Anim. Sci. 2016, 94, 401-405. [CrossRef]

9. Yeruham, I.; Yadin, H.; Haymovich, M.; Perl, S. Adverse reactions to FMD vaccine. Vet. Dermatol. 2001, 12, 197-201. [CrossRef]

10. Perumal, P.; Khate, K.; Rajkhowa, C. Effect of foot and mouth disease vaccination on seminal and biochemical profiles of mithun (Bos frontalis) semen. Asian Pac. J. Reproduction 2013, 2, 178-184. [CrossRef]

11. Kim, D.; Moon, J.; Ha, J.; Kim, D.; Yi, J. Effect of foot-and-mouth disease vaccination on acute phase immune response and anovulation in Hanwoo (Bos taurus coreanae). Vaccines 2021, 9, 419. [CrossRef] [PubMed]

12. Hansen, P.J.; Soto, P.; Natzke, R.P. Mastitis and fertility in cattle-possible involvement of inflammation or immune activation in embryonic mortality. Am. J. Reprod. Immunol. 2004, 51, 294-301. [CrossRef] [PubMed]

13. Rodrigues, M.C.; Cooke, R.F.; Marques, R.S.; Cappellozza, B.I.; Arispe, S.A.; Keisler, D.H.; Bohnert, D.W. Effects of vaccination against respiratory pathogens on feed intake, metabolic, and inflammatory responses in beef heifers. J. Anim. Sci. 2015, 93, 4443-4452. [CrossRef] [PubMed]

14. Yoon, H.; Yoon, S.S.; Wee, S.H.; Kim, Y.J.; Kim, B. Clinical manifestations of foot-and-mouth disease during the $2010 / 2011$ epidemic in the Republic of Korea. Transbound. Emerg. Dis. 2012, 59, 517-525. [CrossRef] [PubMed]

15. Kim, D.; Ha, J.; Yi, J.; Kim, B.; Kwon, W.; Ye, B.; Kim, S.; Lee, Y. Differences in ruminal temperature between pregnant and nonpregnant Korean cattle. J. Anim. Reprod. Biotechnol. 2021, 36, 45-50. [CrossRef]

16. Kim, H.; Oh, S.; Ahn, S.; Choi, B. Real-time Temperature monitoring to enhance estrus detection in cattle utilizing ingestible bio-sensors: Method \& case studies. J. KIIT 2017, 15, 65-75.

17. Choi, W.; Ro, Y.; Hong, L.; Ahn, S.; Kim, H.; Choi, C.; Kim, H.; Kim, D. Evaluation of ruminal motility using an indwelling 3-axis accelerometer in the reticulum in cattle. J. Vet. Med. Sci. 2020, 82, 1750-1756. [CrossRef]

18. Lee, J.I.; Kim, I.H. Pregnancy loss in dairy cows: The contributing factors, the effects on reproductive performance and the economic impact. J. Vet. Sci. 2007, 8, 283-288. [CrossRef]

19. Konnai, S.; Mingala, C.N.; Sato, M.; Abes, N.S.; Venturina, F.A.; Gutierrez, C.A.; Sano, T.; Omata, Y.; Cruz, L.C.; Onuma, M.; et al. A survey of abortifacient infectious agents in livestock in Luzon, the Philippines, with emphasis on the situation in a cattle herd with abortion problems. Acta Trop. 2008, 105, 269-273. [CrossRef]

20. Waldner, C.L. Cow attributes, herd management, and reproductive history events associated with abortion in cow-calf herds from Western Canada. Theriogenology 2014, 81, 840-848. [CrossRef] 
21. Carpenter, T.E.; Chriel, M.; Andersen, M.M.; Wulfson, L.; Jensen, A.M.; Houe, H.; Greiner, M. An epidemiologic study of late-term abortions in dairy cattle in Denmark, July 2000-August 2003. Prev. Vet. Med. 2006, 77, 215-229. [CrossRef] [PubMed]

22. Hassig, M.; Lubsen, J. Relationship between abortions and seroprevalences to selected infectious agents in dairy cows. J. Vet. Med. Sci. 1998, 45, 435-441. [CrossRef] [PubMed]

23. Omori, H.; Otsu, M.; Suzuki, A.; Nakayama, T.; Akama, K.; Watanabe, M.; Inoue, N. Effects of heat shock on survival, proliferation and differentiation of mouse neural stem cells. Neurosci. Res. 2014, 79, 13-21. [CrossRef] [PubMed]

24. Cooper-Prado, M.J.; Long, N.M.; Wright, E.C.; Goad, C.L.; Wettemann, R.P. Relationship of ruminal temperature with parturition and estrus of beef cows. J. Anim. Sci. 2011, 89, 1020-1027. [CrossRef] [PubMed]

25. Bewley, J.M.; Grott, M.W.; Einstein, M.E.; Schutz, M.M. Impact of intake water temperatures on reticular temperatures of lactating dairy cows. J. Dairy Sci. 2008, 91, 3880-3887. [CrossRef] [PubMed] 